Int. J. Dev. Biol. 56: 661-674 (2012)

doi: $10.1387 / \mathrm{ijdb} .120027 \mathrm{mb}$

\title{
Dynamical patterning modules in plant development and evolution
}

\author{
VALERIA HERNÁNDEZ-HERNÁNDEZ ${ }^{1}$ KARL J. NIKLAS², STUART A. NEWMAN³ and MARIANA BENITEZ*,1,4,5 \\ ${ }^{1}$ Centro de Ciencias de la Complejidad, C3, Universidad Nacional Autónoma de México, Mexico, \\ ${ }^{2}$ Department of Plant Biology, Cornell University, Ithaca, NY, USA, \\ ${ }^{3}$ Department of Cell Biology and Anatomy, New York Medical College, Valhalla, NY, USA and \\ ${ }^{4}$ Department of Functional Genomics and Proteomics, CEITEC-Central European Institute of Technology, Brno, Czech Republic, \\ ${ }^{5}$ Departamento de Ecología de la Biodiversidad, Instituto de Ecología, Universidad Nacional Autónoma de México, México.
}

\begin{abstract}
Broad comparative studies at the level of developmental processes are necessary to fully understand the evolution of development and phenotypes. The concept of dynamical patterning modules (DPMs) provides a framework for studying developmental processes in the context of wide comparative analyses. DPMs are defined as sets of ancient, conserved gene products and molecular networks, in conjunction with the physical morphogenetic and patterning processes they mobilize in the context of multicellularity. The theoretical framework based on DPMs originally postulated that each module generates a key morphological motif of the basic animal body plans and organ forms. Here, we use a previous definition of the plant multicellular body plan and describe the basic DPMs underlying the main features of plant development. For each DPM, we identify characteristic molecules and molecular networks, and when possible, the physical processes they mobilize. We then briefly review the phyletic distribution of these molecules across the various plant lineages. Although many of the basic plant DPMs are significantly different from those of animals, the framework established by a DPM perspective on plant development is essential for comparative analyses aiming to provide a truly mechanistic explanation for organic development across all plant and animal lineages.
\end{abstract}

KEY WORDS: dynamical patterning module, plant evo-devo, epigenetics

\section{Introduction}

The dynamic characterization of developmental processes is central to our understanding of the origin and transformation of form, and thus the evolution of phenotypes (Müller, 2007). Since multicellularity in plants and animals appears to have independent origins (Meyerowitz, 2002), studying the dynamics of developmental processes in these two vastly different and diverse kingdoms enables broad comparative studies to discern both generic and particular aspects of development (Meyerowitz, 2002).

Newman and Bhat (2008, 2009; see also Newman, 2011) proposed a useful conceptual framework to characterize and compare basic developmental processes in all multicellular organisms including plants, here broadly defined as all lineages of photosynthetic eukaryotes, including the various polyphyletic algal clades and the monophyletic land plant clade, the embryophytes (see Niklas, 2000; Fig. 1). This framework identifies what are called dynamical patterning modules (DPMs), which are sets of ancient, conserved gene products and networks in association with "generic" (i.e., common to living and nonliving chemically and mechanically excitable systems; Newman and Comper, 1990) physical effects and processes they mobilize in the context of the multicellular state. In animal systems, for example, these physical processes include cohesion, viscoelasticity, diffusion, spatiotemporal heterogeneity due to activator-inhibitor interaction, and multistable and oscillatory dynamics (Newman and Bhat, 2008,2009; Newman, 2011). The DPMs are sufficient to generate the basic features of animal development (multicellularity, segmentation, pattern formation, periodic patterning, appendage formation, etc.). By the definition above, DPMs are inherently associated with the multicellular

\footnotetext{
Abbreviations used in this paper: DIF, differentiation; DPM, dynamical patterning module; DTF, developmental transcription factors; FCW, future cell wall; GRN, gene regulatory network; LLS, leaf-like structure; POL, polarity.
}

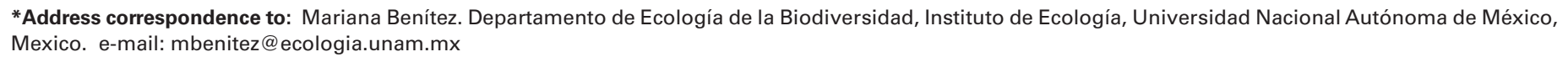


state, though they typically originate by the co-option of genes and regulatory systems already present in the unicellular ancestors of animals (Newman and Bhat, 2009), fungi and plants (see below). In addition, DPMs can act alone or in combination, giving rise to a "pattern language" for the generation of the basic organismic forms of animals and plants (Newman and Bhat, 2008, 2009).

DPMs are assumed to have been uniquely efficacious in the origination of multicellular form, as the generic nature of the DPMassociated physical processes makes it plausible that an assortment of stereotypical forms emerged with relative ease with the rise of multicellularity (Newman, 1994). In present-day developmental systems, the body plan- and organ form-generating DPMs may also continue to operate; however, processes of canalization (Waddington, 1957), stabilizing selection (Schmalhausen, 1949) and developmental systems drift (True and Haag, 2001), may have led to their becoming integrated into more complex pathways.

In conjunction with DPMs, Newman and Bhat (2009) considered the complementary roles of developmental transcription factors (DTFs), which are the products of a different subset of ancient conserved genes from the ones involved in DPMs. The DTFs and their cognate cis-acting elements comprise gene regulatory networks (GRNs), which determine cell fate choice and cell differentiation (Davidson and Erwin, 2006), mainly in a cell-autonomous manner. Together, the DTFs and the DPM-associated molecules and pathways constitute what Carroll (2001) has called the "developmental toolkit". In the case of animals, the gene products enabling the DPMs are an "interaction toolkit" (Newman, 2011), which includes molecules such as cadherins, collagen, Notch, Wnt, Hedgehog and BMP. In postulating a framework in which the interplay between DPMs and DTF-associated GRNs provided the

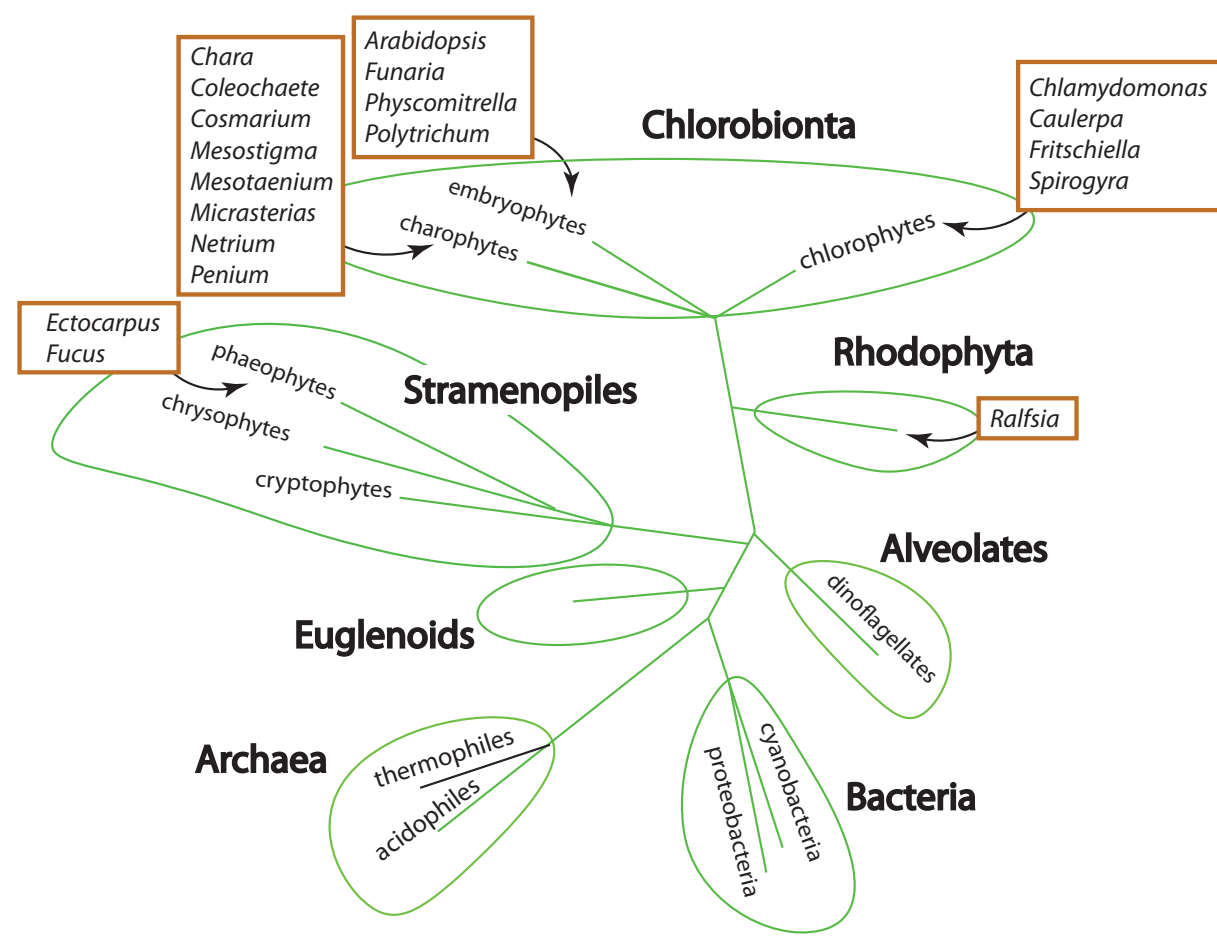

Fig. 1. Redacted schematic of the phylogenetic relationships among the two prokaryotic domains (Archaea and Bacteria) and the five major eukaryotic photoautotrophs, collectively referred to as "plants" (euglenoids, dinoflagellates, rhodophytes, chlorobionta and stramenopiles). raw material for the evolution of the metazoans, Newman and Bhat (2009) also suggested that the evolution of multicellular organisms in other taxonomic groups followed an analogous trajectory (Newman et al., 2006).

Although the evolutionary history and the origin of multicellularity in plants are not as well-described as in animals, our intention here is to outline a DPM catalog for plants. We recognize that this catalog is preliminary and that it will undoubtedly be modified as new insights into plant development become available. Our goal is to inform as best as we can future experimental and theoretical work.

Given that plants and animals are different developmentally in many ways, the nature and role of any DPM operating in plants likely differ from those described for animals by Newman and Bhat (Newman and Bhat, 2009; Newman, 2011). In particular, plant DPMs must incorporate physical limitations on plant development that differ from those that prevail during animal development.

Despite such differences, we suggest that the concepts of DPMs and GRNs can help identify a key set of gene products that mobilize generic physico-chemical processes during plant development. Moreover, even a preliminary set of plant DPMs could be useful for comparative studies of plant and animal development that looks beyond gene homologies, which may not be present or informative, to mechanisms of morphogenesis and pattern formation that may be shared (or not) at the physical level. Indeed, comparing gene sequences has provided valuable insights into the evolution of plants, and performing this type of comparison is arguably easier than comparing more complex entities such as dynamical patterning modules. However, currently available - and growing - evidence reveals that a variety of epigenetic factors ranging from complex regulatory interactions among diverse molecules, to physico-chemical mechanisms, and organism-environment interactions, are necessary for the generation and variation of plant forms (e.g., Perry et al., 2007; Peaucelle etal., 2011; Niklas and Kutschera, 2012; Uyttewaal et al., 2012). Hence, in order to fully understand the development of plant phenotypes, and therefore their evolution, it will be useful to extend the current comparative strategies to include those that allow comparing non-linear and multifactorial modules. Defining a basic set of plant DPMs is an important starting point in this challenging undertaking.

We frame our analysis in terms of the multicellular plant body plan, as defined by Niklas and Kutschera (Niklas, 2000; Niklas and Kutschera, 2009). This body plan is distinguished from the unicellular (e.g., Chlamydomonas), colonial (e.g., Phaeocystis), and siphonous (e.g., Caulerpa) plant body plans by virtue of having symplastic intercellular connections that pass through the walls of some or all adjoining cells. The multicellular body plan has in turn four tissue construction variants: (1) unbranched filaments (e.g., Spirogyra), (2) branched filaments that can be interweaving to give rise to a (3) pseudoparenchymatous tissue construction (e.g., Ralfsia), and (4) a parenchymatous tissue 


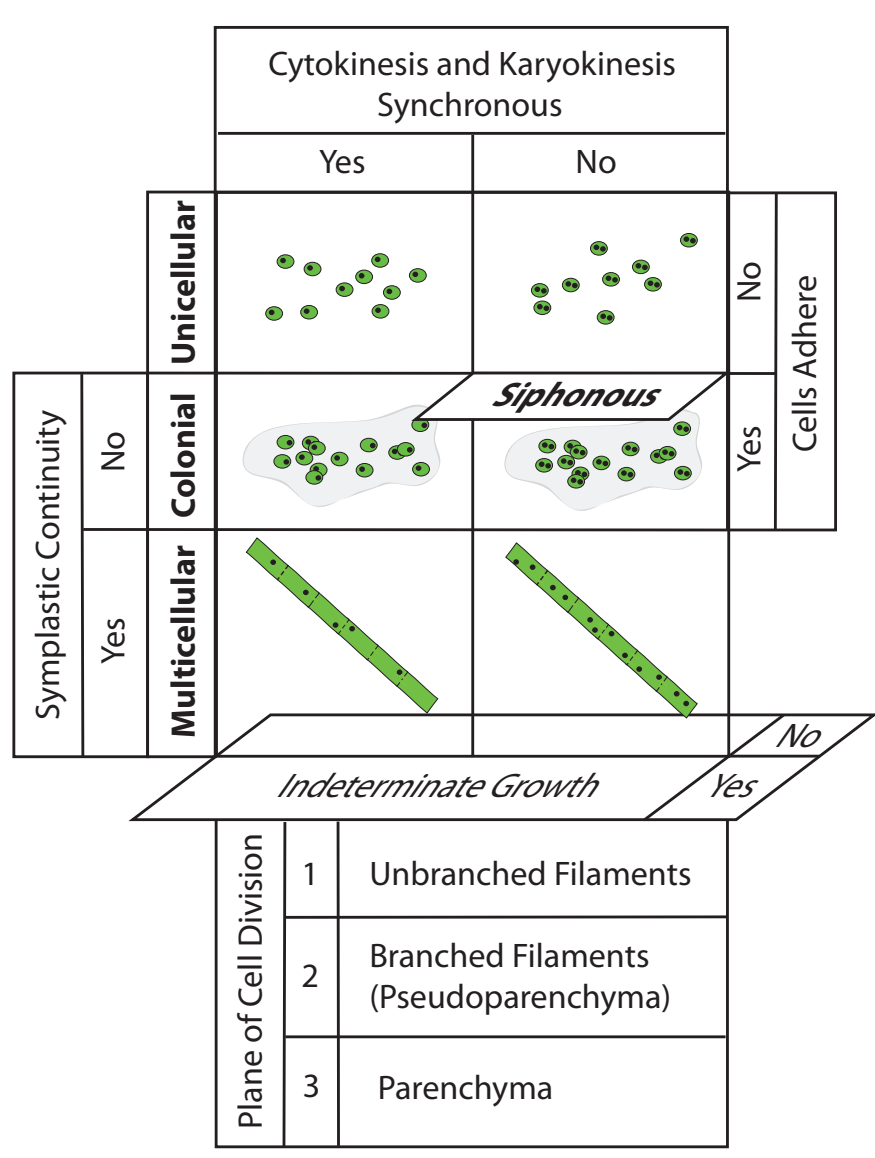

Fig. 2. Developmental features that establish the four plant body plans.

construction, which permits the formation of all other body plan types (characteristic of all land plants) (e.g., Fritschiella).

Although plants, when broadly defined, constitute a polyphyletic group (Schlegel, 1994; Graham and Wilcox, 2000; Niklas, 2000), many of the overall shapes and growth forms observed for plants are strikingly similar among the different lineages, suggesting an important degree of convergence. For these and other reasons, the basic plant body plans, in addition to the common and disparate molecular components employed during their development, can be distinguished on the basis of how they achieve their organized growth (Niklas, 2000). It is in this regard that the DPM concept is particularly relevant in terms of the key developmental processes that produce the different plant body plans: (1) the synchronicity of cytokinesis and karyokinesis, (2) cell-cell adhesion, (3) the establishment of symplastic continuity among adjoining cells, and (4) the plane of cell division (Niklas, 2000; Fig. 2). Our identification of plant DPMs further extends and elaborates on these four processes.

In the following sections we will describe basic features of plant organization and development that in certain aspects set them apart from the animals. We then present a basic preliminary set of DPMs, which in recognition of the tremendous diversity observed across the algal and land plant lineages, is based primarily on the experimental and developmental information available for the widely studied annual vascular plant Arabidopsis thaliana. However, in order to explore the evolutionary origin of these modules, we track as far as currently possible the presence of certain DPM- and
GRN-associated genes and molecules within and across different plant lineages. Next, we compare our proposal with other, complementary, attempts to explain the evolution of plant forms, e.g., in terms of the evolution of certain gene families. Finally, we discuss the novel aspects of plant DPMs relative to those of animals, and draw some conclusions about general principles of multicellular development and its evolution.

\section{Characteristics of plant development and organization}

Even though the DPM framework proposed by Newman and Bhat (Newman and Bhat, 2009; Newman, 2011) is in principle applicable to all multicellular organisms, plant development has features that suggest the presence of additional or different sets of DPMs and perhaps even a different DPM-GRN relationship. In particular, we note that many plants are characterized by having open, indeterminate development during which new tissues and organs are added continuously over the course of their life times. This mode of development reflects the presence of meristems, which are composed of pluripotent cells. Among embryophytes, these stem cells give rise to primary and secondary tissues, as well as generating new organs.

Another distinguishing feature is that plant growth and development are profoundly influenced by environmental cues and factors, such as changes in light, nutrient and water availability, temperature, ecological interactions, etc. The result is a high degree of developmental plasticity which can produce different morphologies among conspecifics (and even among the same organs of a single individual). Nevertheless, several developmental features help to characterize recurrent plant structures that are outcomes of potentially generic patterning and morphogenetic processes.

In addition to its indeterminate and highly plastic nature, we note two other fundamental features of plant development. The first is that plant cells have relatively rigid cell walls such that morphogenesis must occur in the absence of cell migration to generate spatiotemporal patterns. Therefore, programmed cell death and differential asymmetric cell division and growth (e.g., De Smet and Beeckman, 2011), as well as the dynamic emergence and regeneration of spatial boundaries and regions take on particular importance in plant development (Scheres, 2001; Kim and Zambryski, 2005). In this context, "spatially dependent differentiation" refers to the generation of distributions of cell types associated with heterogeneous patterns of signals. These patterns are not necessarily instructive chemical fields passively interpreted by cell arrays (Wolpert, 1996), but may self-organize during development by complex interactions among genetic and epigenetic elements (Salazar-Ciudad et al., 2003; Benítez et al., 2011; Balaskas et al., 2012).

Second, phytohormones such as auxins, cytokinins, ethylene, abscisic acid, gibberellins, brassinosteroids, jasmonic acid, etc., play a central role in the formation of temporal and spatial patterns during development. Although major aspects of their synthesis, degradation, transport and cross-regulation have long been known (see Taiz and Zeiger, 2002), plant hormones and their signaling systems have only been intensively studied from a genetic and molecular perspective in recent years. In particular, the developmental role and the molecular mechanisms associated with auxin have been extensively characterized (Leyser, 2011; Wabnik et al., 2011). It is now clear that auxin, in conjunction with 
other phytohormones, participates in the regulation of manifold developmental transitions and participates in defining regions that correspond to particular structures and cell types (Niklas and Kutschera, 2012).

Another key feature of plant development is also closely related to the non-migrating nature of plant cells and to the dynamics of spatially dependent differentiation. In the case of animal development, it is relatively easy to distinguish between gene products and molecules belonging to an interaction toolkit involved in global DPM-mediated morphogenesis and pattern formation from those (primarily DTFs) involved in intracellular developmental events, such as cell-fate determination (Newman and Bhat, 2009). However, in many of the best-studied developmental systems of the plant model $A$. thaliana, it is commonly observed that transcription factors involved in cell-fate determination are also involved in global patterning processes, e.g., flower organ determination (Urbanus et al., 2010), epidermal cell patterning (Kurata et al., 2005) and meristem subspecification in the root (Cui et al., 2007). Indeed, it has been shown that the mobilization of transcription factors and other molecules through plasmodesmata (channels traversing cell walls and enabling transport and communication between cells), plays a central role during plant developmental processes (Kim and Zambryski, 2005). Although intercellular transport of developmental transcription factors is not unknown in animal systems, it is extremely rare (Prochiantz, 2011).

In addition to being a continuum relative to the action of developmental transcription factors, plant tissues are permissive to the direct cell-cell transport of soluble signaling factors such as auxins and other phytohormones. In contrast to animal morphogens, these molecules can act intracellularly as transcriptional modulators and determinants of the differentiated state (see, for example, Garrett et al., 2012). Nevertheless, unlike animal morphogens, phytohormones exert a more direct transcriptional regulation and have a strong morphological impact during the whole life cycle of the organism. The direct transcriptional roles of morphogens, like the aforementioned cell-to-cell transport of transcription factors, blur the functional separation of GRNs (single-cell determinants of cell differentiation) and DPMs (multicell determinants of pattern formation and morphogenesis) seen in animal development (Newman and Bhat, 2008, 2009).

\section{Basic dynamical patterning modules (DPMs) in plants}

Herein, we present each of the postulated DPMs in the context of what we consider key developmental events and processes in plants. We also discuss the possible origin of these modules in the light of the presence of the characteristic molecules they deploy in different plant lineages. Some of these modules have been studied by other authors (e.g., Green, 1962; Lindenmayer, 1975; Sachs, 1991), and have been postulated as important mechanisms in plant development and evolution. In this contribution, we present these mechanisms in the context of recent experimental evidence and integrate them within the theoretical framework of dynamical patterning modules.

\section{Future cell wall (FCW)}

A critical developmental module in plant evolution is a system that defines the orientation and location of the cell wall during cell division, which in turn results in the formation of different types of tissue construction (Niklas, 2000). Among the charophycean algae and the embryophytes, the location of the future cell wall is prefigured by the appearance of the preprophase band and the phragmoplast (Brown and Lemmon, 2011). The mechanisms underlying the orientation and location of these cytological features are under investigation but not well understood (see for example Gibson and Gibson, 2012). However, early in the 20th century, workers reported that the application of pressure to a dividing cell forced the mitotic figure into the position in which the longitudinal axis was oriented at right angles to the applied pressure such that the future cell wall was oriented parallel to this direction (Kny, 1902; see also Lynch and Lintilhac, 1997). Likewise, Steward and coworkers (1958) noted that cells in free suspension have highly irregular and unpredictable planes of division, perhaps because they are not restricted peripherally as they would when cells normally grow within the plant body. Among certain colonial cyanobacteria, flagellates, and pollen sporocyctes wherein cell divisions are simultaneous, the planes of successive division tend to be at right angles to one another such that regular patterns of two, four, eight, etc. form, all in one plane (Geitler, 1951). A complementary geometric view of this process is known as Errera's rule and has recently been explored as a modeling approach (Besson and Dumais, 2011).

That biomechanically induced mechanical stresses may be involved in cell wall orientation is consistent with many observations (e.g., Corson et al., 2009, although see Mirabet et al., 2011). The simplest plant cells are parenchyma cells, which have thin primary walls and are therefore hydrostatic. The turgor pressure exerted against the walls of these cells is more or less uniform. However, at the vertices created by adjoining cells, opposing tensile stresses are resolved into additional stresses acting in the radial direction on the angle of each vertex according to its size. In theory, the tensile stresses in walls at $180^{\circ}$ should be equal and opposite and thus this angle experiences no additional radial stress from the resolution of the opposing tensile stresses in the two intersecting walls. However, these tensile stresses are resolved into progressively larger radial stresses as the angle of a vertex decreases, reaching their maxima as the angle approaches $0^{\circ}$. Because these additional radial stresses are correlated directly to the size of the angle, a cell reaches mechanical equilibrium at equiangular vertices. Consequently, the observation that the vertices in the region of isodiametrical expansion can act as cellular pivots for wall rotation between successive divisions (so as to coincide with cellular mechanical equilibria) provides some evidence for the biomechanical regulation of cell shape (Niklas and Spatz, 2012).

This biomechanical scenario is vastly different from that operating in an elongating cell (e.g., xylem fiber), wherein existing walls rotate around their vertices to align either perpendicular or parallel to the longitudinal axis and future cell walls are generally oriented perpendicular to the growth axis. Here, the principal stress trajectories likely resolve the global stress patterns into orthogonal components and are thus likely to be oriented parallel and perpendicular to the growth axis. In this condition, cell walls may be oriented so as to minimize shear stresses.

Neither of these scenarios addresses the issue of whether cell walls directly transduce radial stresses into specific cell shapes, or whether mechano-sensitive elements in the cell membrane or cytoskeleton take on or augment this function. However, it is reasonable to suppose that a 'future cell wall" (FCW) module exists, that it is ancient, and that it involves physical cues resulting from 
mechanical stresses operating in preexisting cell walls resulting from hydrostatic pressures (Table 1; Fig. 3).

The effects on multicellular organization of intracellular patterning processes in a founder cell such as an egg or stem cell have been discussed for animal systems under the rubric of "autonomous" patterning mechanisms (Salazar-Ciudad et al., 2003). Because DPMs only come into play in animal embryos when a critical number of cells have been generated (e.g., at the morula or blastula stage), it has been suggested that disparate autonomous patterning processes that may occur in the eggs of subphylum taxa serve mainly to set the initial and boundary conditions for DPM implementation, with conservation of DPM-determined "phylotypic" body plans (Newman, 2011). However, because of the immobility of plant cells, an autonomous patterning mechanism like FCW would be expected to have more profound consequences for plant body plan organization, placing it more in the DPM category. The biological differences between plants and animals are thus manifest even at this most basic level.

\section{Cell-cell adhesion (ADH)}

One of the requisites for multicellularity is the presence of mechanisms and molecules that enable cell-cell adhesion $(A D H)$, which is achieved in different ways in plants, animals and fungi (Knox, 1992; Abedin and King, 2010; Wolf et al., 2012). Among the land plants, cells remain together mainly due to the presence of pectin polysaccharides in the middle lamella associated with the primary cell walls of adjoining cells, which constitute the so-called pectic matrix in which other structural cell-wall components, such as cellulose, hemicellulose and lignin are embedded (Knox, 1992; Willats et al., 2001; Jarvis et al., 2003) (Fig. 3).

The cell wall constitutes one of the characteristic features of plant cells and, arguably, its presence has significantly affected the evolution of plant development. As noted, the cell wall restricts cell mobility, precluding a role for cell migration in plant development. Indeed, the cell wall begins to be formed from cell plates during cytokinesis, such that cell adhesion is the default state (Knox, 1992; Jarvis et al., 2003), which confers mechanical strength by virtue of an "endoskeleton" in the multicellular plant body plan (Niklas, 1992). Additionally, the proportion and chemical state (e.g., level of esterification) of each of the cell wall components is spatiotemporally regulated over the course of development, locally as well as globally, adjusting the mechanical properties of cells and tissues, and contributing to the regulation of cell and organ growth, as well as to organogenesis (Jarvis et al., 2003; Peaucelle et al., 2011). Moreover, diverse mechanisms for pattern formation have evolved in the presence of the plant cell wall.

The original proposal of dynamical patterning modules maintains that modules typically have their origin in the co-option of genes and regulatory systems already present in the unicellular ances- tors of animals, and potentially plants and fungi (Newman and Bhat, 2009). The evolution of cell adhesion can then be studied in plants by exploring the evolution of the cell wall, and particularly, by investigating the presence of pectin polysaccharides and other components of the wall in different plant lineages, including the algae, as well as in groups of unicellular organisms that are closely related to plants. For example, embryophytes and charophycean algae share a common unicellular ancestor that undoubtedly had cell walls (Graham, 1996; Niklas and Kutschera, 2012). However, the question of whether the unicellular ancestors of land plants had the cell-wall molecules that enable cell-cell adhesion remains open, as the composition of the cell wall considerably differs among extant orders of the charophycean algae (Sørensen et al., 2011).

Some cell wall components have ancient origins while others have emerged with specific plant taxa or plant tissues (Sørensen et al., 2011). Primary cell walls are mainly conformed by cellulose microfibrils bound together by cross-linking hemicelluloses that include xyloglucans (XyG), xylans, arabinoxylans, mannans and mixed-linkage $(1 \rightarrow 3)$, $(1 \rightarrow 4)$ - $\beta$-D-glucan (MLG). In turn, the primary cell wall is embedded in a matrix of pectin polysaccharides that include homogalacturonan (HG), rhamnogalacturonan I (RGI) and ramnogalacturonan II (RGII), as well as some proteins and proteoglycans (Ridley et al., 2001). The secondary wall of vascular plants contains more hemicelluloses than pectins and is reinforced by the phenylpropanoid polymer lignin (Boerjan et al., 2003).

The cellulose synthase genes (CesA) are widespread among eukaryotes and prokaryotes (Popper et al., 2011). Remarkable molecular homologies exist among the functionally non-redundant CesA genes across diverse clades, and the presence of these genes in diverse lineages (including animals) may be the result of lateral gene transfers during the origins of eukaryotic lineages (Niklas, 2004). Ultrastructural comparisons of the trans-membrane complexes containing CesA proteins support this hypothesis (Delmer, 1999; Richmond and Somerville, 2000; Nobles et al., 2001; Roberts et al., 2002). All members of the CesA gene family isolated from embryophytes encode for integral membrane proteins with one or two transmembrane helices in the $\mathrm{N}$-terminal protein region, three to six transmembrane helices in the $\mathrm{C}$-terminal region, and an $\mathrm{N}$-terminal domain structure that includes a cytoplasmic loop of four conserved regions (U1-U4), each of which contains a $D$ residue or the QXXRW sequence, which is predicted to code for glycosyltransferase functionality (Richmond and Somerville, 2000). Three additional shared features are a CR-P region between the $\mathrm{U} 1$ and $\mathrm{U} 2$ conserved regions, an N-terminal LIM-like zinc-binding domain, and a region between U2 and U3 (Delmer, 1999) that is conserved within specific clades (Vergara and Carpita, 2001).

Molecular comparisons indicate that the CR-P insertion and the D-D-D-QXXRW motif evolved before the appearance of the embryophytes - indeed, before that of eukaryotes - because both

\section{TABLE 1}

\section{PLANT DYNAMICAL PATTERNING MODULES (DPMS)}

\begin{tabular}{|c|c|c|c|}
\hline DPM & Characteristic molecules & Physical processes & Evo-devo role \\
\hline$\overline{F C W}$ & Cell wall components, possible mechanosensitive elements & Mechanical stress & Defines the orientation and location of the cell wall \\
\hline$A D H$ & Cell wall components, mainly pectin polysaccharides & Adhesion & Formation of multicellular organisms \\
\hline DIF & Plasmodesmata components & Diffusion, reaction-diffusion-like mechanisms & Pattern formation and cell type specification \\
\hline$P O L$ & Auxin, auxin polar transporters, and cell wall components & Mechanical stress & Polarity, axis formation and elongation \\
\hline$B U D$ & Auxins, auxin polar transporters, expansins, and cell wall components & Lateral inhibition and buckling, deformation & Periodic formation of buds and lateral roots \\
\hline LLS & Cell wall components & Buckling, compression-expansion & Formation and shaping of leaf-like structures \\
\hline
\end{tabular}


features have been identified in CesA proteins from the green alga Mesotaenium caldariorum (Roberts et al., 2002) and in CesA-like proteins from cyanobacteria (Nobles etal., 2001). Thus, the genome for cellulose biosynthesis may be traceable to the endosymbiotic origins of chloroplasts, a key event in the history of life. Subsequent gene duplication and functional divergence occurred after ancient CesA-like genes were integrated within eukaryote genomes, because eukaryotic CesA proteins are functionally non-redundant and are arranged in structurally well defined transmembrane structures, called terminal complexes, which are invariably involved in cellulose assembly and deposition into the cell walls of the Phaeophyta, Chrysophyta, Chlorophyta, and Embryophyta (Kutschera, 2008).

Among other cell wall components, XyG epitopes have been found in Netrium digitus, Chara coralina, Coleochaete nitellarum and Cosmarium turpiniand and to a lesser extent in Spirogyra sp. (Sørensen et al., 2011). A XyG endotransglucosylase activity and a putative XyG endotransglucosylase/hydrolase enzyme were detected in Chara vulgaris (Van Sandt et al., 2007). RGIl has not been found in charophycean green algae, but it is possible that they are capable of synthesizing the backbone of RG. Two rare 2-keto sugars 2-keto-3deoxyoctonate (KDO) and 3-deoxy-2heptulosaric acid (DHA) that are present in RGIl also occur in the elaborate scales of some prasinophyte algae (Becker et al., 1998) and DHA occurs in Mesostigma viride(Domozych et al., 1991). This indicates
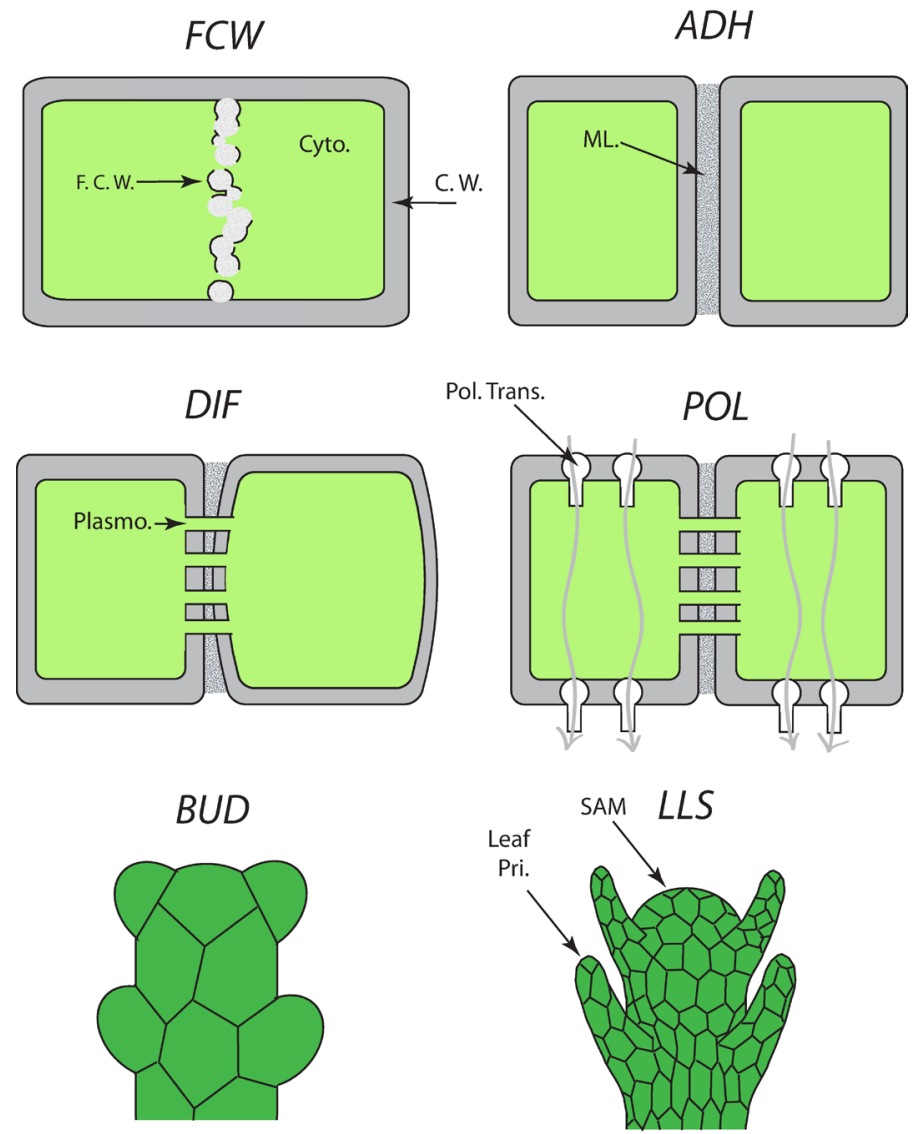

Fig. 3. Schematic representation of the six dynamical patterning modules. (see Table 1). Abbreviations: CW, cell wall; Cyto., cytoplasm; FCW, future cell wall; Leaf. Pr., leaf primordium; Plasmo., plasmodesmata; Pol. Trans., transmembrane polar transporter; SAM, shoot apical meristem. the early evolution of an RGII-like core structure and its posterior diversification during the evolution of embryophytes (Sørensen et al., 2011).

Xylans seem to be present in vascular plants, hornworts and red algae (Popper et al., 2011; Sørensen et al., 2011). Also, Ostreococcus, the smallest known eukaryote and a member of the charophycean green algae, contains several glycosyl transferases that differ from those found in land plants, but which might have a role in xylan biosynthesis (Popper et al., 2011). Other cell wall components that could have been an inheritance from algal ancestor are mannans, HG and arabinogalactans (Sørensen et al., 2011). HG has been detected in the walls of the unicellular desmid Penium margaritaceum and in the charalean species $C$. coralina (Sørensen et al., 2011). This supports the hypothesis that many cell wall features of land plants evolved prior to terrestrialization (Sørensen et al., 2011; Popper et al., 2011).

Overall, these studies suggest that plant unicellular ancestors had at least some of the cell-wall components that underlie cell-cell adhesion and that these were co-opted in the transition to multicellularity. The production of an external envelope of mucoids, or of a composite of calcium pectate and hemicelluloses, is widespread in the cyanobacteria and in the brown, red, and green algal lineages. In addition to protecting cells from herbivores, these materials function as an attachment mechanism to substrata and in the fertilization of water suspended gametes (Graham and Wilcox, 2000). That these components could have been recruited to the organization of multicellular tissues can be inferred from the behavior of an analogous fungal system: certain genotypes of the generally unicellular yeast Saccharomyces cerevisiae can aggregate (Smukalla et al., 2008) or remain attached postmitotically (Ratcliff et al., 2012) under various genetic or environmental conditions.

\section{Spatially dependent differentiation (DIF)}

Embryophytes, and many algal lineages with a multicellular body plan (sensu Niklas, 2000), exhibit cell differentiation. Indeed, most of them have meristematic regions, either apical or intercalary, in which proliferation and differentiation zones are maintained in a steady, yet dynamic balance. An important mechanism for the maintenance of zones with a particular cell identity is the inheritance of a cellular fate through cell lineages (Scheres, 2001). This is especially evident in the root of $A$. thaliana, where cells of a particular type are arranged in lines of cells belonging to the same lineage (Scheres, 2001). However, the de novo specification of cellular identities and regions within the plant body seems to rely mostly on asymmetric cell division (De Smet and Beeckman, 2011) and on the generation of spatiotemporal patterns that distinguish a cell or a region from its neighbors (Scheres, 2001).

For this DPM, we focus on the spatially dependent differentiation and patterns that underlie key events in cell-fate determination and organogenesis. We term this the spatially dependent differentiation (DIF) DPM (Table 1; Fig. 3). In contrast to animal embryos in which cell differentiation is mediated mainly by intracellular GRNs (not DPMs), and pattern formation controlled by several distinct DPMs involving cell rearrangement (Newman and Bhat, 2008, 2009), plant cells walls preclude local rearrangement. Significantly, however, such walls have channels that allow symplastic movement of molecules between cells (Kim and Zambryski, 2005). In this manner, rather than cells, molecules such as transcription factors, peptides, RNA, auxins and other morphogens, migrate or 
translocate during plant development. Symplastic communication relying on the presence of these channels (plasmodesmata) (Raven et al., 2005) has been identified by Niklas (2000) as a diagnostic characteristic of the multicellular plant body plan. By enabling fluxes of molecules across cell boundaries, plasmodesmata interconnect intracellular regulatory networks and play a central role in the formation of spatiotemporal patterns of gene expression at the whole organism level (Kim and Zambryski, 2005; Lucas et al., 2009; Lehesranta et al., 2010).

Although membrane transporters are not involved, the plasmodesmata-mediated movement of molecules appears to be tightly regulated and to depend on the type and size of the mobile molecule, as well as on the particular tissue, and developmental stage (Kim and Zambryski, 2005). Although the details of this type of regulation are only starting to be uncovered, an important aspect of spatially dependent differentiation through cell-cell communication is that it constitutes a dynamic process in which differentiating cells and developing tissues play an active role in setting up the signaling system that pattern them - in contrast to the dissociation between these roles suggested by cells "reading "or "interpreting"positional information (Wolpert, 1996). As noted, unlike animal development, transcription factors and the GRNs in which they participate may act transcellularly during plant development, whereas globally transported morphogens can act at the transcriptional level (e.g., Garrett et al., 2012). Insofar as this is true, cell fate determination and multicellular patterning are inseparable, justifying the designation of a plant-specific spatially dependent differentiation DPM.

Some of the best-studied plant developmental systems involve the movement of molecules through plasmodesmata (see reviews in Kim and Zambryski, 2005; Benítez et al., 2011; Tusscher and Scheres, 2011). For example, symplastic cell-to-cell communication is necessary for the establishment and maintenance of meristems, which are fundamental for the continuous growth and patterning of multicellular plants. In the root apical meristem and in the vascular meristem of $A$. thaliana the establishment of the regions harboring pluripotential cells, as well as the regulation of proliferation and differentiation in these regions during post-embryonic development, require the cell-to-cell movement of transcription factors or other regulatory molecules through plasmodesmata (e.g., Tusscher and Scheres, 2011; Perilli et al., 2012).

In principle, the presence of symplastic channels can mobilize physical processes that have been shown to contribute to pattern formation and that are thus part of the DIF DPM (Table 1). The most obvious of these processes is simple passive diffusion. In turn, intercellular concentration gradients generated by diffusion can contribute to the regulation of gene expression, the cell cycle, and other intracellular processes. Moreover, it has been proposed that in some plant developmental systems, plasmodesmata enable a type of generic physico-chemical patterning mechanism known as reaction-diffusion (Pesch and Hülskamp, 2004; Jönsson et al., 2005; Benítez et al., 2011), which also includes lateral inhibition mechanisms (see below).

Reaction-diffusion systems (RD), as originally proposed by Turing (1952), consist of two or more chemicals that react with each other and that are able to diffuse. Depending on its diffusion and reaction rates, the chemical system can produce complex concentration patterns, ranging from spaced-out dots to fringes and labyrinths. Examples in plant development exist in which complex patterns of cell types seem to emerge, at least in part, from RD-like mechanisms (Benítez et al., 2011). However, as is the case with the utilization of this mechanism in animal patterning (Kondo and Miura, 2010; Zhu et al., 2010), in these systems, there seems to be sets of genes and gene products, and tissue-scale transport processes in addition to diffusion collectively behaving like a RD system, rather than a simple pair of reacting and diffusing chemicals. Indeed, regulatory processes underlying pattern formation in plants may be dynamically richer than RD systems, e.g., they may exhibit redundancy at the gene or at the "circuit"level in ways that confer the patterning systems with dynamic properties that are atypical of simple RD systems (Benítez et al., 2011).

Plasmodesmata are present in embryophytes and the charophycean algae (collectively called the streptophytes), since current evidence suggests that these intercellular connections are homologous (Graham et al., 2000). This homology, however, does not address the origins of these symplastic connections in terms of the last common unicellular ancestor of this large lineage. The origin of plasmodesmata and plasmodesmata-like structures among the various plant lineages may be the result of lateral gene transfer during primary or secondary endosymbiotic events (Niklas, 2000). Multicellularity has evolved in some cyanobacteria (photosynthetic bacteria), which possess small channels that cross walls of neighboring cells. Since chloroplasts likely evolved from a symbiotic event with cyanobacteria, it is possible that part of the genetic toolkit for constructing symplastic conduits in the various algal lineages trace their evolutionary origins to the cyanobacteria. Whether or not this is the case, it will be important to study the evolution of particular molecules involved not only in plasmodesmata structure, but also those involved in the regulation of molecular trafficking through plasmodesmata (Lucas et al., 2009).

\section{Polarity and the determination of the apical-basal axis (POL)}

Among multicellular plants, the polarization of the body axis relies to a great extent on cell-level polarization processes. These can change in response to internal and external cues, making the establishment and maintenance of cell polarity, and concomitant organ polarity, a plastic process during plant development. Here, we describe the POL dynamical patterning module that appears to underlie short and long-range polarization, as well as the specification of an apical-basal growth axis. This DPM involves the phytohormone auxin and the mechanical forces generated in the plant cell-wall (Table 1; Fig. 3).

Auxin is involved in a large spectrum of developmental processes, including cell expansion and differentiation (Taiz and Zeiger, 2002; Niklas and Kutschera, 2012). Among the vascular plants, auxin is synthesized in shoot and root apical meristems from which it can be transported symplastically or through extracellular spaces (apoplastic transport). In the former case, the family of PIN-FORMED (PIN) auxin efflux carriers is largely responsible for the formation of auxin gradients, as the localization of these transporters in particular regions of the cell membrane creates and directs auxin fluxes. Moreover, PINs can be continually rearranged and re-targeted to different regions of the cell membrane. The positioning of PINs provides a mechanism that establishes the directionality of auxin fluxes, whereas the repositioning of PINs provides a mechanism to change the polarity of cell, tissue, or organ growth. Importantly, polarity can be defined at the cell level and at the organ level and while they are tightly linked, the two do not necessarily coincide (e.g., in the shoot apex PIN1 polarity is well-defined while there 
is no overall polarity in the central and peripheral zone). The detailed mechanisms responsible for establishing, maintaining, and changing PIN arrangement are just beginning to be uncovered. It appears, however, that they may involve the regulation of trafficking of intracellular vesicles, the regulation of cytoskeleton alignment, or other signaling events (for a recent review, see Niklas and Kutchera, 2012).

The plant cell wall is another important factor in determining cell polarity because the rate and direction of cell growth involves the disposition and arrangement of the cell wall components (Cosgrove, 2005), and it occurs in the direction dictated by a set of physical forces. From a mechanical perspective, the mature cell wall is a rigid composite that exerts a hydrostatic compressive force when the protoplast it surrounds is turgid. Any permanent increase in the volume of the protoplast (i.e., growth) requires the loosening of the cell wall, which permits the influx of water and an increase in cell volume (Cosgrove, 2005). Cell wall loosening allows for wall stress relaxation (i.e., a reduction in cell wall mechanical stresses) (Niklas, 1992; Cosgrove, 2005; Mirabet et al., 2011). Consequently, when the cell wall is relaxed, turgor pressure provides the mechanical energy that is required to expand the cell (Cosgrove, 2005; Boudaoud, 2010; Mirabet et al., 2011). However, the direction of cell growth depends on the extent to which cell wall constituents (primarily, cellulose microfibrils) are uniformly or asymmetrically distributed in the cell wall. If stress-resisting constituents are homogeneously distributed, cell expansion is more or less uniform (isotropic growth). If these constituents are heterogeneously distributed, cell expansion is anisotropic. Polar cell growth, therefore, requires a prefigured deposition of cell wall stress-resisting constituents (Niklas and Spatz, 2012).

Experimental evidence in $A$. thaliana and other plant models indicates that auxin flow and cell-wall forces reciprocally interact during the emergence of polarity. Auxin promotes polar expansion through cell wall loosening, probably by means of the acidification of the apoplast and the concomitant disruption of non-covalent bonds among cell wall polysaccharides (Cosgrove, 2005). In turn, the preferential localization of PINs (or their transporting vesicles), which determines auxin fluxes, may target where cell wall loosening occurs (Heisler et al., 2010).

We propose that auxin mobilization and the effects of auxin on the mechanical properties of the cell wall provide a DPM that establishes the polarity of the body axis throughout the multicellular plants. It is likely that elements of this module were present in unicellular plants since the cell walls of unicellular algae are not mechanically isotropic and manifest morphologies that are distinctly non-spherical. In addition, endogenous auxin has been identified in some multicellular algae (Boot et al., 2012), even in lineages that are not related to the green algal and land plant clade (e.g., the brown alga Ectocarpus siliculosus, in which auxin might play a crucial role in the elongation of the filamentous thallus; Le Bail et al., 2010). Likewise, the effects of auxins on the dynamics of the cytoskeleton of unicellular charophycean algae appear to be similar to those observed for embryophytes (Jin et al., 2008).

Innovations in auxin biosynthesis and metabolism have led to more precise regulation of auxin levels (Cooke et al., 2002; Křeček et al., 2009) and the origination and diversification of the auxin transporters (e.g., plasma membrane PINs) have contributed to the diversification of land plant body plans (Zažímalová et al., 2010). However, although Fujita and collaborators (2008) detected auxin fluxes in the sporophyte of three species of mosses, Physcomitrella patens, Funaria hygrometrica and Polytrichum commune, they found no evidence for auxin fluxes in gametophytic "shoots" nor did they find any putative orthologs of plasma membrane PIN transporters. Additionally, De Smet and coworkers (2011) concluded that mosses do not posses plasma membrane PINs but may have putative orthologs for PINs localized in the membrane of the endoplasmic reticulum. These and other lines of evidence indicate that some type of anisotropic auxin mobilization (sensu Wabnik et al., 2011) or some other, still-unknown transporters may be involved in the formation of auxin fluxes in algae and mosses (e.g., Boot et al., 2012). If true, the potentially generic POL module may have evolved from some form of anisotropic auxin mobilization that did not necessarily involve plasma membrane PINs but instead involved cell wall mechanical stresses.

That the POL DPM may draw on ancient physiological properties of the plant cell can be inferred from the studies of Jaffe and coworkers on rhizoid formation during the embryogenesis of the brown alga, Fucus (Jaffe, 1969; Peng and Jaffe, 1976). All eukaryotic cells are capable of generating intracellular spatiotemporal transients in calcium ion concentration. In Fucus, the position of the rhizoid, a morphological protuberance of the cell that is the first sign of developmental polarity, is not predetermined, but is induced in the fertilized egg by an asymmetric calcium flux from the cell elicited by a light gradient or any of a number of different biochemical manipulations which mobilize and organize this generic unicellular functionality (see also discussion in Smith and Grierson, 1982).

\section{Periodic formation of buds (BUD)}

As noted, auxin participates in the DIF and POL dynamical patterning modules. Here, we propose a third module in which auxin plays a significant role, but in which the key physical process is lateral inhibition. This is the periodic formation of buds and lateral roots (BUD) DPM (Table 1; Fig. 3).

After germination, the typical vascular land plant continues to grow and develop new roots, stems, and leaves. New roots are added as a result of the endogenous development of new root apical meristems. In contrast, new stems and leaves are the result of the exogenous development of leaf primordia, which develop into a variety of leaf-types (e.g., bracts, foliage leaves, and petals) and axillary buds, which can develop into new shoots. The shoot apical meristem produces leaf primordia in a highly regulated process that gives rise to different arrangements of leaves, e.g., different phyllotactic patterns (Douady and Couder, 1996; Reinhardt, 2005; Besnard et al., 2011). The stereotypical phyllotactic patterns (alternate, opposite, whorled or spiral), which are found in almost all vascular land plants (Reinhardt, 2005), can change during plant development. For example, many plants transit from an initial decussate phyllotaxis to a spiral pattern, during reproductive development, and finally to whorled phyllotaxis during floral development (Reinhardt, 2005). These transitions suggest the existence of a potentially common organogenic mechanism behind all phyllotactic patterns (Reinhardt, 2005; Jönsson et al., 2005; Newell et al., 2008) that can be studied, at least partially, by investigating the mechanisms that specify the positions of leaf primordia (Jönsson et al., 2005; Besnard et al., 2011).

Several experiments indicate that preexisting primordia influence the location of new ones (Reinhard, 2005; Bohn-Courseau, 
2010). This phenomenology was the basis for the hypothesis that the formation of new primordia is mediated by the diffusion of an inhibitory molecule that blocks the emergence of primordia next to each other (see review in Reinhardt, 2005). According to this hypothesis, each primordium is an auxin sink and the distance between newly formed primordia depends on the concentration of a negative regulator that peaks in the position of an emerging primordium and decreases with increasing distance from this site. At some threshold level, the inhibitor ceases to prevent the formation of other primordia.

In the general case, this hypothesis invokes a lateral inhibition mechanism that, theoretically, suffices to generate observed phyllotactic patterns rigorously conforming to the mathematical Fibonacci series. As Douady and Couder (1996) showed theoretically, and experimentally, using a nonliving system of sequentially deposited magnetic droplets, a generic self-organizing process depending on the successive appearance of new elements that are repelled from each other gives rise to periodic patterns similar to the phyllotactic ones. Moreover, this mechanism provides a physical system in which comparatively small changes in one or few parameters give rise to transitions in phyllotactic patterns (Douady and Couder, 1996).

The processes that underlie this kind of a lateral inhibition mechanism in living plants remain unknown. Recently, however, the development of molecular-genetic tools has provided the means to test whether such a mechanism exists in model organisms like $A$. thaliana (Reinhardt, 2005). For example, mutants in auxin transport, synthesis or perception fail to produce normal phyllotactic arrangements and often develop leafless shoots (Bohn-Courseau, 2010; Besnard et al., 2011). These and other mutants indicate that auxin plays an important role during the formation and positioning of new organs (Benková et al., 2003; Reinhardt et al., 2003; Reinhardt, 2005). The lateral inhibition mechanism is consistent with the observation that organ initiation sites are loci of high levels of auxin activity (Benková et al., 2003; Reinhardt, 2005; BohnCourseau, 2010), the observation that organ removal or ablation affects subsequent organ positioning (Reinhardt, 2005), and that the loss of function mutation of the auxin transporter PIN1 results in a shoot that produces leaves but (almost) no flowers (Reinhardt et al., 2003). These and other data support the proposition that auxin constitutes or contributes to the generation of patterns necessary for organ arrangement in vascular plants and possibly also in other plant lineages (Benková et al., 2003; Křeček et al., 2009; BohnCourseau, 2010; Zazímalová et al., 2010; Wabnik et al., 2011).

The role of polar auxin transport in the generation of phyllotactic patterns is further supported by in silico experiments that reproduce observed patterns based on the assumption that auxin maxima initiate organ formation (e.g., Jönsson et al., 2005). However, instead of requiring the diffusion of an inhibitor molecule, these computer models indicate that phyllotaxis may be determined by the formation of auxin peaks and valleys (Bohn-Courseau, 2010) in a manner that is similar to the "canalization" mechanism put forward by Sachs some decades ago (Sachs, 1991). (Canalization sensu Sachs involves a self-sustained concentration of auxin in particular sites, in contrast to canalization sensu Waddington (1957), which refers to a developing organism's ability to produce the same phenotype despite variation in genotype or environment).

In addition to auxin, expansins have been suggested to act as primordia initiators (Reinhardt et al., 1998; Fleming, 2006). As discussed in the context of the POL DPM, there appears to be a relation between the local mechanical properties of the wall and the localization of auxin transporters. Indeed, it has been proposed that the effects of physical forces acting on the cell wall might play a key role in primordia formation and phyllotactic patterning (Newell et al., 2008; Kierzkowski et al., 2012; for a review see Besnard et al., 2011). For instance, it has been suggested that the rapid growth of hypodermal cells in the shoot apical meristem exerts forces on the tunica, such that when outer cell walls are loosened, these compressive forces give rise to buckling patterns that closely resemble the pattern of emerging primordia (Green et al., 1996; Newell et al., 2008; Kierzkowski et al., 2012). In this scenario, lateral inhibition between primordia is mediated or reinforced by mechanical forces.

Liquid deformations, involving, e.g., viscous flow and surface tension (Manning et al., 2010), are part of some of the proposed animal DPMs (Newman and Bhat, 2008, 2009). The liquidity of animal tissues, however, relies on the individual mobility of cells, which is not observed in developing plant tissues. Instead, plastic deformation, which in physics refers to the non-reversible changes of a material in response to applied forces, seems to play an important role in plant growth.

Even though most plant tissues are viscoelastic solids, and many are truly rigid solids (Niklas, 1992) the growth of plant cells requires that cell walls become locally plastic, by means of cell wall loosening, and deform under the force of turgor pressure, and subsequently rigidify. Indeed, this deformation allows the cell to increase its size permanently. Even if it is embedded in relatively rigid tissue, or in rapidly growing tissues, the cell walls of groups of cells can remain in phase, going through episodes of coordinating softening and hardening. Expansins have been associated with both elastic (i.e., reversible) and plastic (i.e., irreversible) changes in the plant cell wall (Cosgrove, 2000). These effects reinforce auxin patterns and thus contribute to the process by which different types of mechanical forces contribute to the specification of new buds (BUD DPM) (see Kierzkowski et al., 2012).

Expansins have been found or predicted to be present in several lineages of embryophytes (Cosgrove, 2000; Carey and Cosgrove, 2007) and recent investigations suggest that these proteins are also present in Micrasterias denticulata (Vannerum et al., 2011), a green algae belonging to closest extant unicellular relatives of land plants. This, along with the phyletic distribution patterns of auxin and auxin transport (see discussion for POL DPM), suggest that co-option of molecular mechanisms already present in unicellular plants may have provided the basis for the BUD DPM.

\section{Formation and shaping of leaf-like structures (LLS)}

As first suggested by J. W. Goethe (1790), recent theoretical studies based on experimental data (Pelaz et al., 2001) indicate that floral organs and all other exogenously growing appendicular structures can be classified as leaves. Therefore, it is reasonable to speculate that another module in plant development may involve the formation and shaping of leaf-like structures (LLS, Table 1; Fig. 3).

Leaf shape in particular is attained by anisotropic growth in several axes: the adaxial-abaxial, medial-lateral and proximal-distal. The bulge formed by a feedback between biophysical and biochemical signals (BUDDPM) extends to create a functional leaf-like structure and it has been hypothesized that in such growing organs, the inner tissues are the driving forces for expansion, whereas the 
outer tissues impose mechanical constraints and restrict the cell expansion and organ growth (Fleming, 2006; Kutschera and Niklas, 2007). This proposal has been called epidermal-growth control; just as the cell wall is a rigid structure that keeps the cell contents under compression, restricts cell expansion and prevents the cell from exploding, the epidermis and cuticle confines the expansion of internal tissues during the growth of leaves and stems (Kutschera and Niklas, 2007).

As described for the BUD DPM, the maturation of leaves may involve interactions among the mechanical forces generated by the epidermis and hypodermal cells. The balancing of these mechanical forces postulated to occur in leaf-like organs (Kutschera, 1989) may generate buckling phenomena that determine organ curvatures and other aspects of leaf morphogenesis (Moulia, 2000; Dumais, 2007). Another component of the LLS DPM may be the action of morphogens controlling the oriented growth and tissue deformation during leaf growth, as suggested by a recent study using time-lapse imaging, clonal analysis and computational modeling (Kuchen et al., 2012).

Besides growth, leaf structure and physiology are influenced by polarization patterns that establish the future distribution of cell

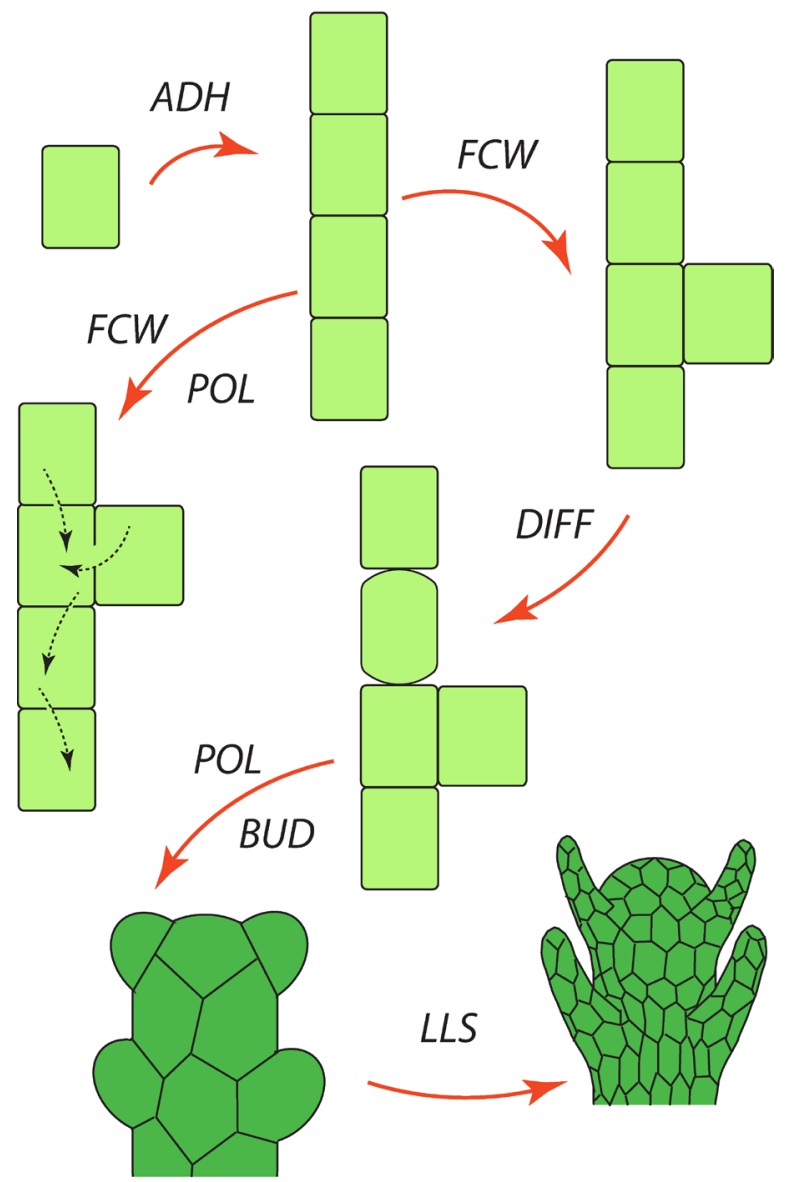

Fig. 4. The combination of the dynamical patterning modules (DPMs) in different parts of an organism, and at different stages of development may give rise to the basic multicellular plant body plan. The documented interactions among DPMs suggest that these modules may act simultaneously or in an alternating manner along plant development, therefore, this figure illustrate only one possible - although arguably common - sequence of DPM action and combination. types (Moon and Hake, 2011). For example, cells in the adaxial surface of the lamina are more important for light harvesting than cells above the abaxial side, which play a more important role in gas exchange. In this regard, Fleming (2006) has suggested that changes in patterns of cell division respond to and induce mechanical signals that participate in subsequent developmental events (see FCWDPM). The resulting new patterns of cell division may in turn establish patterns of plasmodesmatal connections, ensuring that "groups of cells entering a particular developmental pathway share relevant transcriptional information" in a way that they constitute "separate entities" (Fleming, 2006). This could explain how specific families of transcription factors are expressed by groups of cells in the specification of leaf axes such as HD-ZIPIII family and KANADI in the adaxial and abaxial sides, respectively (Braybrook and Kuhlemeier, 2010; Moon and Hake, 2011). Another, nonexclusive explanation relies on the local production and apoplastic transport of ligands or other types of signals that contribute to the emergence of different expression profiles and the specification of "plasmodesmatal domains" within an organ.

Finally, leaf shape and vasculature differentiation are intimately connected (Tsukaya, 2006). For example, auxin gradients generated by polar transport and canalization sensu Sachs (POL DPM) determine the location of procambial cells that will subsequently differentiate into the xylem and phloem (Sachs, 1991; Fujita and Mochizuki, 2006) in ways that link the LLS and POL modules.

As is the case for other DPMs, the evolution of the LLS DPM is also tightly associated with the evolution of the cell wall components, many of which could have been co-opted during the early evolution of multicellular plants from pre-existing molecules and processes. While, to the best of our knowledge, the information required to situate the $L L S$ module outside embryophtes (e.g., for the laminar structures of bryophyte gametophytes) is still scarce, this module offers a working hypothesis to continue studying this process in other plant lineages.

\section{Discussion}

We have presented a preliminary set of dynamical patterning modules (DPMs) associated with critical plant developmental events (Table 1) and have specified some of the physical and molecular components of these modules. On the basis of the phyletic distribution of the molecular elements of the DPMs, we have also hypothesized that, as in animal systems, these modules originated from co-option of cell-molecular mechanisms that had first evolved in association with single-cell functions in the unicellular ancestors of the various plant lineages which mobilized, in the multicellular context, novel physical processes such as the internal mechanical stresses generated as cells or tissues expand and grow. One of our central conclusions is that not all of the information required for plant development needs to be encoded genetically. Once development is set into operation, much of it becomes self-organizing. Additionally, we suggest that the combination of different DPMs at different places and developmental stages may be sufficient for the generation of the basic features of the multicellular plant body plan (Fig. 4).

We have assumed (as suggested by the "module" nomenclature) that DPMs are semi-autonomous, which allows them to be defined and studied separately. However, the proposed DPMs have been shown to interact with one another, sometimes establishing 
negative and positive feedback systems. Indeed, it is the dynamic combination and changing links among DPMs that could contribute to the striking plasticity of plant development. For instance, it has been observed that the relative positions of cell walls change with cell growth and that the FCW module may also depend on cell polarity (Dhonukshe et al., 2012).

DPMs provide a framework for comparing developmental processes at a dynamic, epigenetic level, utilizing processes not encoded directly in the DNA sequence. The methods to systematically perform such comparative analyses and infer evolutionary relations are still relatively primitive. However, mathematical and computational models will be extremely useful as tools to study the collective action of a set of interacting molecules and physical processes constituting a DPM, as well as to test the behavior of potential modifications of these modules with changes due to mutation of DPM-enabling genes, or geometric context. For example, Zhu and coworkers (2010) have developed a model for the system of DPMs associated with limb development in vertebrates and have modeled modified versions that may correspond to the alteration of relevant biological parameters, offering a mechanistic explanation for the development and evolution of vertebrate limbs.

Additionally, DPMs serve as new evolutionary hypotheses that are testable at many levels. The original DPM proposal suggests that the combination of DPMs had an important role in the evolutionary origin of animal body plans and their early diversification (Newman and Bhat, 2008, 2009). Specifically, this proposal suggests that early multicellular organisms were phenotypically plastic, which permitted them to rapidly explore morphospace. In turn, the relatively stable developmental trajectories and morphological phenotypes of modern organisms are a result of canalization (e.g., via gene duplication and subspecialization) and stabilizing selection. Indeed, it has been hypothesized that the collective action of animal DPMs could have underlain the diversification of bilaterian animal forms during the so-called Cambrian explosion (Newman, 2012).

Here we speculate that, as suggested for animal systems, the combined action of relatively flexible DPMs had a central role in the evolution and diversification of plant body plans. This view contrasts with the hypothesis that land plant diversification resulted mainly from the expansion of particular gene families, such as PINs (Zažímalová et al., 2010), or that the evolution of the embryophytes was predominantly the result of hormonal dynamics (Cooke et al., 2003). Certainly, while these molecules are central for plant development and, most probably also for plant morphological evolution, we argue that the notion that diversification of certain gene families or molecules classes can be the main cause of morphological evolution is likely insufficient if not fundamentally flawed (Niklas and Kutschera, 2012). In light of inconclusive searches for "master" molecules of animal embryogenesis (e.g., attempts to identify the molecular basis of the vertebrate "organizer"; Slack, 2002), we believe that plant development is the result of a set of dynamical systems that act synergistically in complex ways. In this picture, gene products do not have fixed developmental roles over the course of evolution, but take on new functions in different contexts.

More broadly, the DPM concept may help overcome the limitations of comparing and studying the evolution of genes or gene families. For example, PINs do not seem to be expressed in moss gametophytes. Nevertheless, the DPM formalism supports the investigation of cellular and organ polarity on the basis of interactions between analogous ancient physiological and cell-wall properties that do not rely on PINs.

As was the case in the evolution of animal development (Newman and Bhat, 2009), generic physical effects were mobilized during the early evolution of multicellular plants by particular gene products and pathways. During this phase of evolution, some molecules (an "interaction toolkit" very different from that of the metazoans) assumed critical importance in the development and continue to do so among present-day plants. For example, auxin, which is involved in regulating embryo and postembryonic development in modern vascular plants, and is thus an important molecule in two of the DPMs described here (Table 1), played a crucial role in the diversification of land plant phenotypes during the Late Silurian to Early Devonian Periods (Cooke et al., 2003; Niklas and Kutschera 2009 , 2012). Additionally, our current knowledge of auxin action and regulation suggests that major changes in auxin action occurred in the earliest land plants before the Late Silurian (Cooke et al., 2003). However, the central role of auxin in plant development and evolution cannot be understood without considering equally ancient cell wall components, auxin transporters, etc. (Niklas and Kutschera, 2012) as well as the physical processes collectively mobilized by these molecules and their respective DPMs (Table 1).

Like auxin, cell wall components are involved in all of the proposed DPMs, suggesting that the presence of a cell wall played a pivotal role in determining and influencing the types of physical processes that predominate during plant development. The mechanical forces generated within and by plant cell walls stand in contrast to those postulated for animal DPMs, which permit cell rearrangement and deformations in a physical system that is largely defined by fluid as opposed to solid mechanics (Newman and Bhat, 2008, 2009). This difference suggests to us that the DPMs of multicellular fungi might be more similar to those of plants than animals despite the biochemical differences between the cell walls of fungi and plants and the phylogenetic affinities of the fungi and the metazoans (Shalcchian-Tabrizi et al., 2008).

Another difference between plant and animal DPMs concerns the extent to which they are developmentally 'flexible' in evolutionarily more derived lineages. The original proposal concerning animal DPMs postulated that these modules were initially flexible in terms of phenotypic outcome but that they became integrated into more robust and less plastic developmental processes, possibly via canalization (sensu Waddington) and selection. This may have also been the case for plant development and evolution but to a lesser degree for lineages in which sessile multicellular organisms evolved. In these lineages, it is reasonable to conjecture that natural selection would have favored plants that retained implementation of more plastic DPMs, particularly those with an open indeterminate growth pattern in which new tissues or organs are added indefinitely over the course of a life-time. Less rigidly integrated systems of DPMs would permit development to track changes in ambient environmental conditions, which can change sometimes dramatically over the course of long-lived species such as trees. This conjecture is amenable experimentally to falsification by means of broad developmental comparisons among unicellular versus multicellular organisms and determinate versus indeterminate species.

Finally, related to these questions of plasticity and flexibility are insights into the mechanistic bases of these phenomena in plants afforded by the DPM framework. In comparisons of animal 
and plant biology it has always been somewhat paradoxical that multicellular plants, with their "solid" tissue structure, are actually more variable ecophenotypically and more capable of regenerating lost parts, propagating vegetatively, morphologically accommodating grafts across species lines, and even forming new species by hybridization, than their largely soft-tissued animal counterparts. Considering plant development from the viewpoint of the DPMs described above, it becomes clear that plant development, much more so than animal embryogenesis, organizes matter that is dynamic over large scales, utilizing inherently multicellular systems of multifunctional hormones/morphogens/transcription factors which are unrestricted by cell boundaries in many of their functions. Under such conditions, the repurposing of adult tissues for development, and the capacity to assume novel, ecologically adaptive, morphological phenotypes within individual lifetimes, becomes less enigmatic.

\section{Acknowledgements}

The authors would like to thank Elena R. Alvarez-Buylla, Alma PiñeyroNelson, Mario A. Pacheco, Ricardo Chávez, EugenioAzpeitia, the members of the De Folter (LANGEBIO) group, the members of the Theoretical Biology Seminar at the Centro de Ciencias de la Complejidad C3, an anonymous reviewer, as well as the participants in the Summer School on Evolutionary Developmental Biology (Venice, 2011) for valuable discussions and comments regarding the ideas presented in this review. M.B. was supported by the "CEITEC - Central European Institute of Technology" project (CZ.1.05/1.1.00/02.0068) from the European Regional Development Fund.

\section{References}

ABEDIN M, KING N (2010) Diverse evolutionary paths to cell adhesion. Trends Cell Biol 20: 734-742.

BALASKAS N, RIBEIRO A, PANOVSKAJ, DESSAUD E, SASAI N, PAGE KM, BRISCOE J, RIBES V. (2012). Gene regulatory logic for reading the Sonic Hedgehog signaling gradient in the vertebrate neural tube. Cell 148: 273-284.

BECKER B, MELKONIAN M, KAMERLING JP (1998). The cell wall (theca) of Tetraselmis striata (Chlorophyta): macromolecular composition and structural elements of the complex polysaccharides. J. Phycol 34: 779-787.

BENITEZ M, MONK N, ALVAREZ-BUYLLA ER (2011). Epidermal patterning in Arabidopsis: models make a difference. J Exp Zool B Mol Dev Evol 316: 241-253.

BENKOVÁ E, MICHNIEWICZ M, SAUER E, TEICHMANN T, SEIFERTOVÁ D, JÜRGENS G, FRIML J. (2003). Local, efflux-dependent auxin gradients as a common module for plant organ formation. Cell 115: 591-602.

BESNARD F, VERNOUX T, HAMANT O (2011). Organogenesis from stem cells in planta: multiple feedback loops integrating molecular and mechanical signals. Cell Mol Life Sci: CMLS 2885-2906. doi:10.1007/s00018-011-0732-4

BESSON S, DUMAIS J (2011). Universal rule for the symmetric division of plant cells. Proc Nat Acad Sci USA 108: 6294-6299.

BOERJAN W, RALPH J, BAUCHER M (2003). Lignin biosynthesis. Annu Rev Plant Biol 54: 519-546.

BOHN-COURSEAU I (2010). Auxin: a major regulator of organogenesis. CR Biologies 333: 290-296.

BOOT KJ, LIBBENGA KR, HILLE SC, OFFRINGA R, VAN DUIJN B (2012). Polar auxin transport: an early invention. J Exp Bot 63:4213-4218.

BOUDAOUD A (2010). An introduction to the mechanics of morphogenesis for plant biologists. Trends Plant Sci 15: 353-360.

BRAYBROOK S, KUHLEMEIER C (2010). How a plant builds leaves. Plant Cell 22: 1006-1018.

BROWN RC, LEMMON BE (2011). Dividing without centrioles: innovative plant microtubule organizing centres organize mitotic spindles in bryophytes, the earliest extant lineages of land plants. AoB PLANTS 2011: plr028; doi:10.1093/aobpla/plr028.

CAREYRE, COSGROVEDJ (2007). Portrait of the expansin superfamily in Physcomitrella patens: comparisons with angiosperm expansins. Ann Bot 99: 1131-1141.
CARROLLSB (2001). Chance and necessity: the evolution of morphological complexity and diversity. Nature 409: 1102-1109.

COOKE TJ, POLI D, COHEN JD (2003). Did auxin play a crucial role in the evolution of novel body plans during the Late Silurian--Early Devonian radiation of land plants? In The evolution of plant physiology: from whole plants to ecosystems (Eds Alan R. Hemsley, Imogen Poole). Linnean Society of London, London, pp. 85-107.

COOKE TJ, POLI D, SZTEIN AE, COHEN JD (2002). Evolutionary patterns in auxin action. Plant Mol Biol 49: 319-338.

CORSON F, HAMANT O, BOHN S, TRAAS J, BOUDAOUD A, COUDER Y (2009). Turning a plant tissue into a living cell froth through isotropic growth. Proc Nat Acad Sci USA 106: 8453-8458.

COSGROVE DJ (2000). Expansive growth of plant cell walls. Plant Physiol Biochem 38: 109-124.

COSGROVE DJ (2005). Growth of the plant cell wall. Nature Rev Mol Cell Biology 6: 850-861.

CUI H, LEVESQUE MP, VERNOUX T, JUNG JW, PAQUETTE AJ, GALLAGHER KL, WANG JY, BLILOU I, SCHERES B, BENFEY PN (2007). An evolutionarily conserved mechanism delimiting SHR movement defines a single layer of endodermis in plants. Science 316: 421-425.

DAVIDSON EH, ERWIN DH (2006). Gene regulatory networks and the evolution of animal body plans. Science 311: 796-800.

DE SMET I, BEECKMAN T (2011). Asymmetric cell division in land plants and algae: the driving force for differentiation. Nat Rev Mol Cell Biol 12: 177-188.

DE SMET I, VOB U, LAU S, WILSON M, SHAO N, TIMME RE, SWARUP R, KERR I, HODGMAN C, BOCK R, BENNETT M, JÜRGENS G, BEECKMAN T (2011). Unraveling the evolution of auxin signaling. Plant Physiol 155: 209-211.

DELMER DP (1999). Cellulose biosynthesis: Exciting times for a difficult field. Ann Rev Plant Phys Plant Mol Biol 50: 245-276.

DHONUKSHE P, WEITS DA, CRUZ-RAMÍREZ A, DEINUM E, TINDEMANS SH, KAKARK, PRASAD K, MÄHÖNENAP, AMBROSE C, SASABE M, WACHSMANNG, LUIJTEN M, BENNETT T, MACHIDAY, HEIDSTRAR, WASTENEYS G, MULDER BM, SCHERES B. (2012). A PLETHORA-Auxin trasncription module controls cell division plane rotation through MAP65 and CLASP. Cell 149: 383-396.

DOMOZYCH DS, WELLS B, SHAW PJ (1991). Basket scales of the green alga Mesostigma viride: chemistry and ultrastructure. J. Cell Sci 100: 397-407.

DOUADY S, COUDER Y (1996). Phyllotaxis as a dynamical self-organizing process Part I: The spiral modes resulting from time-periodic iterations. J Theor Biol 178: 255-274.

DUMAIS J (2007). Can mechanics control pattern formation in plants? Curr Opin Plant Biol 10: 58-62.

FLEMING AJ (2006). Leaf initiation: the integration of growth and cell division. Plant Mol Biol 60: 905-914.

FUJITA H, MOCHIZUKI A (2006). The origin of the diversity of leaf venation pattern. Dev Dynn 235: 2710 -2721.

FUJITAT, SKAGUCHI H, HIWATASHI Y, WAGSTAFF SJ, ITO M, DEGUCHI H, SATO T, HASEBE M (2008). Convergent evolution of shoot in land plants: lack of auxin polar transport in moss shoots. Evol Dev 10: 176-186.

GARRETT JJ, MEENTSMJ, BLACKSHAWMT, BLACKSHAWLC, HOUH, STYRANKO DM, KOHALMI SE, SCHULTZ EA (2012). A novel, semi-dominant allele of MONOPTEROS provide insight into leaf initiation and vein pattern formation. Planta 236: 297-312.

GEITLER L (1951). Über rechtwinkelige Schneidung von Scheidewänden und dreidimensionale Zellverbände. Osterr. Bot Zeitschr 98: 171-186.

GIBSON WT, GIBSON MC (2012). Growing cells push back under pressure. Cell 149: 259-261.

GOETHE JW (1790). Versuch die metamorphose der pflanzen zu erklären. CW Ettinger, Gotha.

GRAHAM LE (1996). Green algae to land plants: An evolutionary transition. J Plant Res 109: 241-251.

GRAHAM LE, COOK ME, BUSSE JS (2000). The origin of plants: Body plan changes contributing to a major evolutionary radiation. Proc NatAcad SciUSA 97:4535-4540.

GRAHAM LE, WILCOX LW (2000). Algae. Prentice Hall, Upper Saddle River, NJ.

GREEN PB (1962). Mechanism for plant cellular morphogenesis. Science 28: 1404-1405. 
GREEN PB, STEEL CS, RENNICH SC (1996). Phyllotactic patterns: A biophysical mechanism for their origin. Ann. Bot 77: 515-527.

HEISLER MG, HAMANT O, KRUPINSKI P, UYTTEWAAL M, OHNO C (2010). Alignment between PIN1 polarity and microtubule orientation in the shoot apical meristem reveals a tight coupling between morphogenesis and auxin transport. PloS Biol 8 (10) doi:10.1371/journal.pbio.1000516.

JAFFE LF (1969). On the centripetal course of development, the Fucus egg, and self-electrophoresis. Develop Biol Supp/ 3: 83-111

JARVIS MC, BRIGGS SPH, KNOX JP (2003). Intercellular adhesion and cell separation in plants. Plant Cell Environ 26: 977-989.

JIN Q, SCHERP P, HEIMANN K, HASENSTEIN KH (2008). Auxin and cytoskeletal organization in algae. Cell Biol Int 32: 542-545.

JÖNSSON H, HEISLER M, REDDY GV, AGRAWAL V, GOR V, SHAPIRO BE, MJOLSNESS E, MEYEROWITZ EM (2005). Modeling the organization of the WUSCHEL expression domain in the shoot apical meristem. Bioinformatics 21 Suppl. i232 - i240.

KIERZKOWSKI D, NAKAYAMA N, ROUTIER-KIERZKOWSKA AL, WEBER A, BAYER E, SCHORDERET M, REINHARDT D, KUHLEMEIER C, SMITH RS (2012). Elastic domains regulate growth and organogenesis in the plant shoot apical meristem. Science 2: 1096-1099.

KIM I, ZAMBRYSKI PC (2005). Cell-to-cell communication via plasmodesmata during Arabidopsis embryogenesis. Curr Opin Plant Biol 8: 593-599.

KNOX JP (1992). Cell adhesion, cell separation and plant morphogenesis. Plant $J$ 2: $137-141$

KNYL (1902). Über den einfluss von zug und druck auf die richtung der scheidewände in sich theilenden pflanzenzellen. (Zweite Mittheilung.) Jahrb Wiss Bot 37: 55-98.

KONDO S, MIURAT (2010). Reaction-diffusion model as a framework for understanding biological pattern formation. Science 329: 1616-1120.

KŘEČEK P, SKŮPA P, LIBUS J,NARAMOTO S, TEJOS R, FRIML J, ZAŽíMALOVÁ E (2009). Protein family review the PIN-FORMED (PIN) protein family of auxin transporters. Genome Biol 10: 1-11.

KUCHEN EE, FOX S, DE REUILLE PB, KENNAWAY R, BENSMIHEN S, AVONDO J, CALDER GM, SOUTHAM P, ROBINSON S, BANGHAM A, COEN E (2012). Generation of leaf shape through early patterns of growth and tissue polarity. Science 335: 1092-1096.

KURATAT, OKADAK, WADAT (2005). Intercellular movement of transcription factors. Curr Op Plant Biol 8: 600-605.

KUTSCHERA U (1989). Tissue stresses in growing plant organs. Physiol Plant 77: 157-163.

KUTSCHERA U (2008). The growing outer epidermal wall: Design and physiological role of a composite structure. Ann Bot 101: 615-621.

KUTSCHERA U, NIKLAS KJ (2007). The epidermal-growth-control theory of stem elongation: an old and a new perspective. J Plant Physiol 164: 1395-1409.

LE BAIL A, BILLOUD B, KOWALCZYK N, KOWALCZYK M, GICQUEL M, LE PANSE S, STEWART S, SCORNET D, COCK J M, LJUNG K, CHARRIERB. (2010). Auxin metabolism and function in the multicellular brown alga Ectocarpus siliculosus. Plant Physiol 153: 128-144.

LEHESRANTA SJ, LICHTENBERGER R, HELARIUTTA Y (2010). Cell-to-cell communication in vascular morphogenesis. Curr Op Plant Biol 13: 59-65.

LEYSER O (2011). Auxin, self-organisation, and the colonial nature of plants. Curr Biol 21: R331-R337.

LINDENMAYER A (1975). Developmental algorithms for multicellular organisms: A survey of L-systems. J Theor Biol 54: 3-22.

LUCAS WJ, HAM B-K, KIM J-Y (2009). Plasmodesmata - bridging the gap between neighboring plant cells. Trends Cell Bio 19: 495-503.

LYNCH TM, LINTILHAC PM (1997). Mechanical signals in plant development: A new method for single cell studies. Dev Biol 181: 246-256.

MANNING ML, FOTY RA, STEINBERG MS, SCHOETZ EM (2010). Coaction of intercellular adhesion and cortical tension specifies tissue surface tension. Proc Natl Acad Sci USA 107: 12517-12522.

MEYEROWITZ EM (2002). Plants compared to animals: The broadest comparative study of development. Science 295: 1482-1485.

MIRABET V, DAS P, BOUDAOUD A, HAMANT O (2011). The role of mechanical forces in plant morphogenesis. Annu Rev Plant Biol 62: 365-385.
MOON J, HAKE S (2011). How a leaf gets its shape. Curr Op Plant Biol 14: 24-30.

MOULIA B (2000). Leaves as shell structures: double curvature, auto-stresses, and minimal mechanical energy constraints on leaf rolling in grasses. J Plant Growth Regul 19: 19-30.

MÜLLER GB (2007). Evo-devo: extending the evolutionary synthesis. Nat Rev Genet 8: 943-949.

NEWELL AC, SHIPMAN PD, SUN Z. (2008). Phyllotaxis: cooperation and competition between mechanical and biochemical processes. J Theor Biol 251:421-439.

NEWMAN SA (1994). Generic physical mechanisms of tissue morphogenesis: A common basis for development and evolution. J Evol Biol 7: 467-488.

NEWMAN SA (2011). Animal egg as evolutionary innovation: a solution to the 'embryonic hourglass' puzzle. J Exp Zool B Mol Dev Evol 316: 467-83.

NEWMAN SA (2012). Physico-genetic determinants in the evolution of development. Science 338: 217-219.

NEWMAN SA, BHAT R (2008). Dynamical patterning modules: physico-genetic determinants of morphological development and evolution. Phys Biol 5: 15008

NEWMAN SA, BHAT R (2009). Dynamical patterning modules : a 'pattern language' for development and evolution of multicellular form. Int J Dev Biol 53: 693-705.

NEWMANSA, COMPERWD (1990). 'Generic'physical mechanisms of morphogenesis and pattern formation. Development 110: 1-18.

NEWMAN SA, FORGACS G, MULLER GB (2006). Before programs: the physica origination of multicellular forms. Int J Dev Biol 50: 289-299.

NIKLAS KJ (1992). Plant Biomechanics: an Engineering Approach to Plant Form and Function. University of Chicago Press, Chicago, IL.

NIKLAS KJ (2000). The Evolution of Plant Body Plans: A Biomechanical Perspective. Ann Bot 85: 411-438.

NIKLAS KJ (2004). The cell walls that bind the tree of life. BioScience 54: 831-841.

NIKLAS KJ, KUTSCHERA U (2009). The evolutionary development of plant body plans. Funct Plant Biol 36: 682-695.

NIKLAS KJ, KUTSCHERA U (2012). Plant development, auxin, and the subsystem incompleteness theorem. Front Plant Sci 3: 37.

NIKLAS KJ, SPATZH-C (2012). Plant physics. University of Chicago Press, Chicago, IL.

NOBLESDR, ROMANOVICZDK, BROWNRM JR (2001). Cellulose in cyanobacteria Origin of vascular plant cellulose synthase? Plant Physiol 127: 529-542.

PEAUCELLE A, BRAYBROOK SA, LE GUILLOU L, BRON E, KUHLEMEIER C, HÖFTE H (2011). Pectin-induced changes in cell wall mechanics underlie organ initiation in Arabidopsis. Curr Biol 21: 1720-1726.

PELAZS, TAPIA-LÓPEZR, ALVAREZ-BUYLLAER, YANOFSKY MF (2001). Conversion of leaves into petals in Arabidopsis. Curr Biol 11: 182-184.

PENG HB, JAFFE LF (1976). Polarization of fucoid eggs by steady electrical fields. Dev Biol 53: 277-284

PERILLI S, DI MAMBRO R, SABATINI S (2012). Growth and development of the root apical meristem. Curr Op Plant Biol 15: 17-23.

PERRY P, LINKE B, SCHMIDT W (2007). Reprogramming of root epidermal cells in response to nutrient deficiency. Biochem Soc Trans 35(Pt 1): 161-163.

PESCH M, HÜLSKAMP M (2004). Creating a two-dimensional pattern de novo during Arabidopsis trichome and root hair initiation. Curr Opin Genet Devel 14: 422-427.

POPPER ZA, MICHEL G, HERVÉ C, DOMOZYCH DS, WILLATS WG, TUOHY MG KLOAREG B, STENGEL DB (2011). Evolution and diversity of plant cell walls: from algae to flowering plants. Annu Rev Plant Biol 62: 567-590.

PROCHIANTZ A (2011). Homeoprotein intercellular transfer, the hidden face of cellpenetrating peptides. Methods Mol Biol 683: 249-257.

RATCLIFF WC, DENISON RF, BORRELLO M, TRAVISANO M (2012). Experimental evolution of multicellularity. Proc Natl Acad Sci USA 109: 1595-1600.

RAVEN PH, EVERT RE, EICHORN SE (2005). Biology of Plants. W. H. Freeman, New York

REINHARDT D (2005). Regulation of phyllotaxis. Int J Dev Biol 49: 539-546.

REINHARDT D, PESCE ER, STIEGER P, MANDEL T, BALTENSPERGER K, BENNETT M, TRAAS J, FRIML J, KUHLEMEIER C (2003). Regulation of phyllotaxis by polar auxin transport. Nature 426: $255-260$

REINHARDT D, WITTWER F, MANDEL T, KUHLEMEIER C (1998). Localized up regulation of a new expansin gene predicts the site of leaf formation in the tomato meristem. Plant Cell 10: 1427-1437. 
RICHMOND TA, SOMERVILLE CR (2000). The cellulose synthase superfamily. Plant Physiol 124: 495-498.

RIDLEY BL, O'NEILL MA, MOHNEN D (2001). Pectins: structure, biosynthesis, and oligogalacturonide-related signaling. Phytochemistry 57: 929-967.

ROBERTS AW, ROBERTS EM, DELMER DP (2002). Cellulose synthase (CesA) genes in the green alga Mesotaenium caldariorum. Eukaryotic Cell 1: 847-855.

SACHS T (1991). Pattern Formation in Plant Tissues. Cambridge University Press, New York.

SALAZAR-CIUDAD I, JERNVALL J, NEWMAN SA (2003). Mechanisms of pattern formation in development and evolution. Development 130: 2027-2037.

SCHERES B (2001). Plant cell identity: the role of position and lineage. Plant Physiol 125: $112-114$.

SCHLEGELM(1994). Molecular phylogeny of eukaryotes. Trends EcolEvol 9:330-335.

SCHMALHAUSEN II (1949). Factors of Evolution: The Theory of Stabilizing Selection. Blakiston, Oxford.

SHALCHIAN-TABRIZIK, MINGE MA, ESPELUND M, ORRR, RUDENT, JAKOBSEN KS, CAVALIER-SMITHT(2008). Multigene phylogeny of choanozoa and the origin of animals. PLoS One 3:e2098.

SLACK JMW (2002). Conrad Hal Waddington: the last Renaissance biologist? Nat Rev Gen 3: 889-895.

SMITH H, GRIERSON D (1982). The Molecular Biology of Plant Development. University of California Press, Berkeley.

SMUKALLA S, CALDARA M, POCHET N, BEAUVAIS A, GUADAGNINI S, YAN C, VINCES MD, JANSEN A, PREVOST MC, LATGÉ JP, FINK GR, FOSTER KR, VERSTREPEN KJ (2008). FLO1 is a variable green beard gene that drives biofilm-like cooperation in budding yeast. Cell 135: 726-737.

SØRENSEN I, PETTOLINO FA, BACIC A, RALPH J, LU F, O'NEILL M, FEI Z, ROSE JKC, DOMOZYCH DS, WILLATS WGT (2011). The Charophycean green algae provide insights into the early origins of plant cell walls. Plant $J 68: 201-211$

STEWARD FC, MAPES MO, SMITH J (1958). Growth and organized development of cultured cells. I. Growth and division of freely suspended cells. Amer J Bot 45: 693-703.

TAIZ L, ZEIGER E (2002). Plant Physiology. Third Edition. Sinauer Associates, Sunderland Massachusetts.

TRUE JR, HAAG ES (2001). Developmental system drift and flexibility in evolutionary trajectories. Evol Dev 3:109-119.

TSUKAYA H (2006). Mechanism of leaf-shape determination. Ann Rev Plant Biol 57: 477-496.

TURING AM (1952). The chemical basis of morphogenesis. Philos Trans R Soc Lond B Biol Sci 237: 37-72
TUSSCHER K, SCHERES B (2011). Joining forces: feedback and integration in plant development. Curr Op Gen Dev 21: 799-855

URBANUS SL, MARTINELLI AP, DINH QDP, AIZZA LCB, DORNELAS MC, ANGENENT GC, IMMINK RGH (2010). Intercellular transport of epidermis-expressed MADS domain transcription factors and their effect on plant morphology and floral transition. Plant J 63: 60-72.

UYTTEWAALM, BURIANA, ALIMK, LANDREINB, BOROWSKA-WYKRĘTD, DEDIEU A, PEAUCELLE A, LUDYNIA M, TRAAS J, BOUDAOUD A, KWIATKOWSKA D, HAMANT O (2012). Mechanical stress acts via katanin to amplify differences in growth rate between adjacent cells in Arabidopsis. Cell 149: 439-451.

VAN SANDT VS, STIEPERAERE H, GUISEZ Y, VERBELEN JP, VISSENBERG $\mathrm{K}$ (2007). XET activity is found near sites of growth and cell elongation in bryophytes and some green algae: new insights into the evolution of primary cell wall elongation. Ann Bot 99 : 39-51.

VANNERUM K, HUYSMAN MJ, DE RYCKE R, VUYLSTEKE M, LELIAERT F, POLLIER J, LÜTZ-MEINDL U, GILLAR J, DE VEYLDER L, GOOSSENS A, INZÉ D, VYVERMAN W (2011). Transcriptional analysis of cell growth and morphogenesis in the unicellular green alga Micrasterias (Streptophyta) with emphasis on the role of expansin. BMC Plant Biol 11:128.

VERGARA CE, CARPITA NC (2001). Beta-D-glycan synthases and the CesA gene family: lessons to be learned from the mixed-linkage (1->3),(1->4)beta-D-glucan synthase. Plant Mol Biol 47: 145-160.

WABNIK K, GOVAERTS W, FRIML J, KLEINE-VEHN J (2011). Feedback models for polarized auxin transport: an emerging trend. Mol BioSystems 7: 2352-2359 (doi:10.1039/c1mb05109a).

WADDINGTON CH (1957). The Strategy of the Genes:ADiscussion of Some Aspects of Theoretical Biology. George Allen \& Unwin, London.

WILLATS WG, ORFILAC, LIMBERG G, BUCHHOLT HC, VAN ALEBEEK GJ, VORAGEN G, MARCUS SE, CHRISTENSENTM, MIKKELSENJD, MURRAYBS, KNOX JP (2001). Modulation of the degree and pattern of methyl-esterification of pectic homogalacturonan in plant cell walls. Implications for pectin methyl esterase action, matrix properties, and cell adhesion. J Biol Chem 276: 19404-19413.

WOLF S, HÉMATY K, HOFTE H (2012). Growth control and cell wall signaling in plants. Ann Rev Plant Biol 63: 381-407.

WOLPERT L (1996). One hundred years of positional information. Trends Genet 12: $359-364$

ZAŽíMALOVÁ E, MURPHY AS, YANG H, HOYEROVÁ K, HOSEK P (2010). Auxin transporters-why so many? Cold Spring Harb Perspect Biol 2: a001552.

ZHU J, ZHANG YT, ALBER MS, NEWMAN SA (2010). Bare bones pattern formation: a core regulatory network in varying geometries reproduces major features of vertebrate limb development and evolution. PLoS One 5: e10892. 


\section{Further Related Reading, published previously in the Int. J. Dev. Biol.}

Genomic control of patterning

Isabelle S. Peter and Eric H. Davidson

Int. J. Dev. Biol. (2009) 53: 707-716

Dynamical patterning modules: a "pattern language" for development and evolution of multicellular form

Stuart A. Newman and Ramray Bhat

Int. J. Dev. Biol. (2009) 53: 693-705

The emergence of patterning in life's origin and evolution

Robert M. Hazen

Int. J. Dev. Biol. (2009) 53: 683-692

Pattern formation mechanisms in reaction-diffusion systems

Vladimir K. Vanag and Irving R. Epstein

Int. J. Dev. Biol. (2009) 53: 673-681

Limb pattern, physical mechanisms and morphological evolution - an interview with Stuart A. Newman

Cheng-Ming Chuong

Int. J. Dev. Biol. (2009) 53: 663-671

Equivalent genetic regulatory networks in different contexts recover contrasting spatial cell patterns that resemble those in Arabidopsis root and leaf epidermis: a dynamic model Mariana Benítez, Carlos Espinosa-Soto, Pablo Padilla-Longoria, José Díaz and Elena R. Alvarez-Buylla

Int. J. Dev. Biol. (2007) 51: 139-155

Before programs: The physical origination of multicellular forms

Stuart A. Newman, Gabor Forgacs and Gerd B. Müller

Int. J. Dev. Biol. (2006) 50: 289-299

Morphodynamics of phyllotaxis

Alexander G. Malygin

Int. J. Dev. Biol. (2006) 50: 277-287

Morphomechanics: goals, basic experiments and models.

Lev V. Beloussov and Vassily I. Grabovsky

Int. J. Dev. Biol. (2006) 50: 81-92

5 yr ISI Impact Factor $(2011)=2.959$

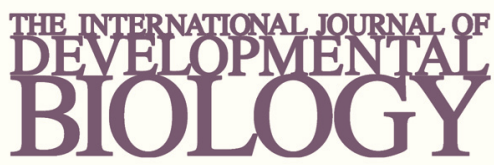

Volume 54 Nos. 6/7
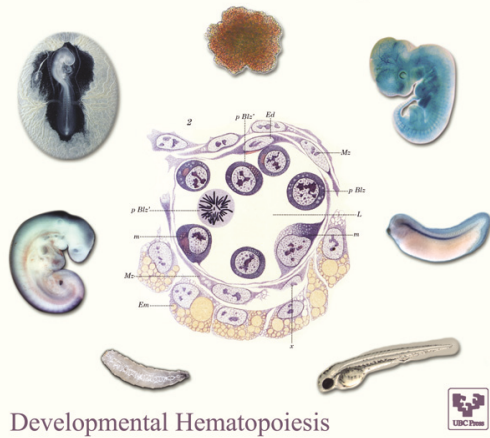
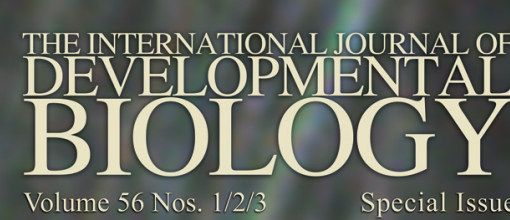

Special Issue
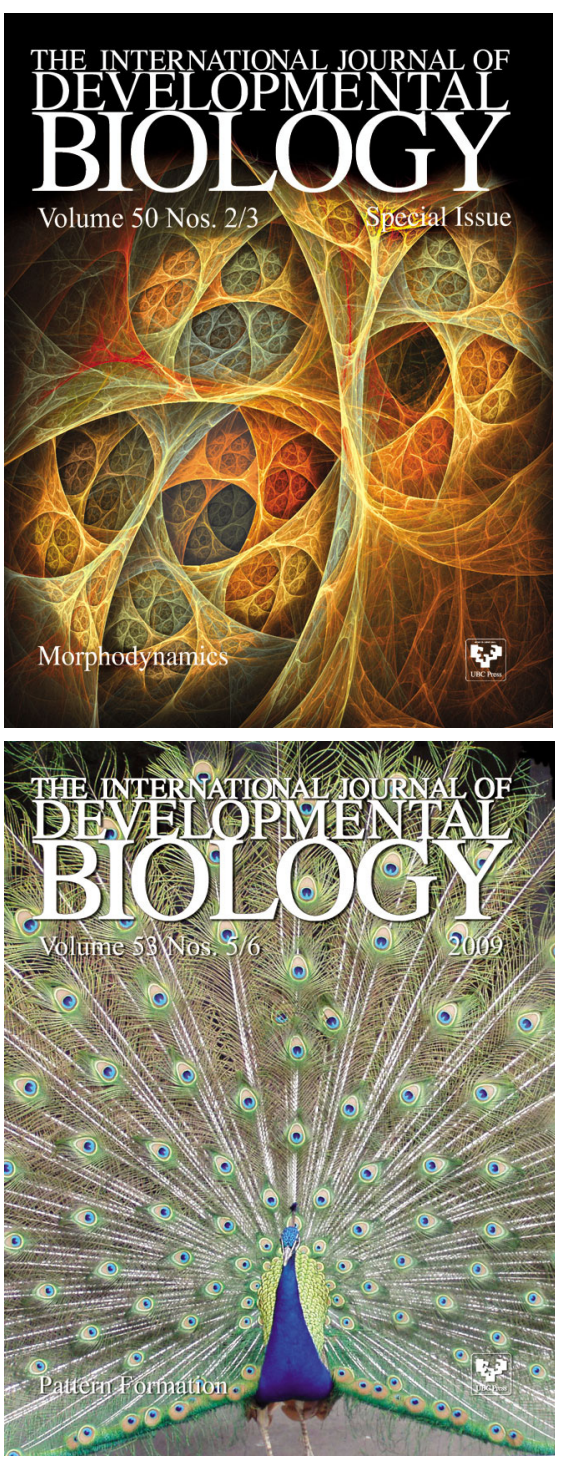